\title{
Defective inhibition of sodium on basophil histamine release in patients with allergic rhinitis and bronchial asthma
}

\author{
A. Tedeschi*, M. Cottini**, C. Salmaso*, N. Milazzo*, A. Miadonna*
}

Defective inhibition of sodium on basophil histamine release in patients with allergic rhinitis and bronchial asthma. A. Tedeschi, M. Cottini, C. Salmaso, N. Milazzo, A. Miadonna. COERS Journals Ltd 1996.

ABSTRACT: The aim of this study was to evaluate whether $\mathrm{Na}^{+}$exerts its inhibitory effect on basophil histamine release induced by immunoglobulin $\mathbf{E}$ (IgE)dependent (anti-IgE) and IgE-independent ( $\mathrm{N}$-formyl-methionyl-leucyl-phenylalanine (FMLP), interleukin-3 (IL-3)) stimuli in patients with allergic rhinitis $(n=24)$ and allergic bronchial asthma $(\mathbf{n}=\mathbf{1 0})$.

Peripheral blood leucocytes were stimulated with anti-IgE, FMLP and IL-3 in the presence of high and low $\mathrm{Na}^{+}$concentrations, and histamine release was measured using a fluorometric method.

In standard $\mathrm{Na}^{+}$-containing medium, spontaneous and stimulated histamine release was higher in allergic patients $(n=34)$ (both rhinitic and asthmatic) than in healthy subjects $(n=41) . \mathrm{Na}^{+}$removal from extracellular medium and its isosmotic substitution with choline chloride or with N-methyl-D-glucamine led to a significant increase of anti-IgE-, FMLP- and IL-3-induced histamine release in normal subjects, but not in allergic patients. The increase in $\mathrm{Na}^{+}$concentration in the extracellular medium was accompanied by a dose-dependent decrease of anti-IgE- and FMLP-induced histamine release in normal subjects, but not in allergic patients. The behaviour of atopics and healthy subjects was different and not related to the basophil responsiveness to activating signals. The incubation of basophils from healthy subjects with sera from allergic patients did not have a significant influence on the inhibitory effect of $\mathrm{Na}^{+}$.

Basophils from healthy subjects and atopic patients respond differently when stimulated in a low $\mathrm{Na}^{+}$medium. The reduced sensitivity to the inhibitory effect of $\mathrm{Na}^{+}$may contribute to basophil dysfunction in patients with respiratory allergy. Eur Respir J., 1996, 9, 2070-2076.

\begin{abstract}
*Respiratory Allergy and Immunology Unit, Dept of Internal Medicine, University of Milan, IRCCS Ospedale Maggiore Policlinico, Milan, Italy. **Allergy and Pneumology Unit, USSL 12, Bergamo, Italy.
\end{abstract}

Correspondence: A. Tedeschi

Pad. Granelli

IRCCS Ospedale Maggiore Policlinico

Via Sforza, 35

I-20122 Milan

Italy

Keywords: Basophils

histamine release

respiratory allergy

sodium

Received: December 281995

Accepted after revision June 301996
Human basophils bear high affinity immunoglobulin $\mathrm{E}(\mathrm{IgE})$ receptors on their membrane and can release potent inflammatory mediators, such as histamine and leukotriene $\mathrm{C}_{4}$, following antigen binding to specific $\mathrm{IgE}$ on the cell membrane [1]. It has been demonstrated that IgE-mediated histamine release from human basophils is not correlated with membrane $\operatorname{IgE}$ density [2], and that the intrinsic capacity of the basophil to respond to activating signals is important in determining the amounts of mediators released [3]. To define the responsiveness to activating agents, the term "releasability" was coined several years ago by LiCHTENSTEIN and co-workers [4].

Although the microenvironment can influence mediator release from basophils, in particular through the action of cytokines, the data collected so far indicate that the intrinsic ability of the cells is an important parameter conditioning mediator release. Basophil releasability is increased in patients with allergic rhinitis and asthma [5-7], and it has been suggested that it may contribute to the pathogenesis of allergic disease. LICHTENSTEIN and co-workers [8] showed that the severity of symptoms in allergic patients during the ragweed season correlated with basophil sensitivity to antigen stimulation in vitro. A correlation has been found between basophil number in peripheral blood and bronchial hyperresponsiveness as assessed by methacholine challenge in asthmatic patients [9]; therefore, the enhanced basophil releasability that has been observed in patients with respiratory allergy may be of clinical significance.

Although, in the last few years, much progress has been made in the understanding of the biochemical pathways involved in mediator secretion from human basophils, the causes of the enhanced basophil releasabillty have not yet been defined. It has been demonstrated that $\mathrm{Ca}^{2+}$ plays an important role in signal transduction and basophil histamine release [10-11]; however, other cations, such as $\mathrm{Na}^{+}$and $\mathrm{K}^{+}$, participate in the regulation of basophil histamine release [12-13]. $\mathrm{Na}^{+}$influx inhibits histamine release, whereas $\mathrm{K}^{+}$efflux has an enhancing effect [13]. The inhibition by $\mathrm{Na}^{+}$profoundly affects basophil releasability, since anti-IgE-nonreleasing basophils are converted into releasing basophils when they are suspended in a low $\mathrm{Na}^{+}$medium [14]. After removal of $\mathrm{Na}^{+}$from extracellular medium, basophils from normal subjects acquire the capacity to release histamine on challenge with a weak agonist, such as interleukin-3 
(IL-3) [15]. The inhibitory effect of $\mathrm{Na}^{+}$is altered in patients with allergic rhinitis [16], and this impairment coexists with an enhanced releasability. Furthermore, a defect in $\mathrm{Na}^{+}$metabolism and $\mathrm{Na}^{+}$transport across biological membranes in allergic patients has been postulated by some authors [17-19]. SKONER et al. [17] found a reduction of $\mathrm{Na}^{+}, \mathrm{K}^{+}$adenosine triphosphatase enzyme activity in the platelets of allergic patients, due to a circulating inhibitor. TRIBE et al. [18] showed that patients with airway hyperresponsiveness had increased $\mathrm{Na}^{+}$ influx into peripheral blood leucocytes, stimulated by a serum-borne factor. It is not clear how these biochemical alterations could influence the expression of allergic manifestations, but it has been hypothesized that they could cause an increase of airway reactivity and an altered responsiveness or function of a large number of cell types.

The aim of this study was to evaluate the effect of $\mathrm{Na}^{+}$on basophil histamine release induced by IgE-dependent and IgE-independent stimuli in patients with allergic rhinitis and asthma. We have found that the inhibitory activity of $\mathrm{Na}^{+}$on basophil histamine release is impaired in patients with either allergic rhinitis or bronchial asthma and that the defective inhibition concerns both IgEdependent and IgE-independent stimuli.

\section{Subjects and methods}

\section{Patients and control populations}

The patients were selected among the subjects followed by the out-patient allergy clinic, Ospedale Maggiore Policlinico, Milan and by the Allergy Unit, USSL 12, Bergamo. Normal healthy subjects were used as controls and were recruited from the hospital staff and the faculty students; informed consent was obtained from all patients and control subjects before venous blood collection. Twenty four patients with allergic rhinitis (12 males), 10 patients with mild allergic bronchial asthma ( 7 males) and 41 healthy subjects ( 23 males) were included in the study. The mean age ( \pm SEM) of the allergic patients was $28 \pm 2$ yrs and the mean age of the control subjects was $37 \pm 1$ yrs. Respiratory allergy was diagnosed on the basis of a detailed clinical history and skin-prick tests. The allergens involved were grass pollen $(\mathrm{n}=25)$, Dermatophagoides pteronyssinus $(\mathrm{n}=13)$, birch pollen $(\mathrm{n}=2)$ and Parietaria judaica $(\mathrm{n}=2)$. Seven patients reacted to two or more allergens. Neither allergic nor control subjects were taking any medication at the time of blood collection.

\section{Sample collection and preparation of leucocyte sus- pensions}

Leucocyte suspensions were prepared by dextran sedimentation of peripheral venous blood $(60-80 \mathrm{~mL})$, anticoagulated with $0.01 \mathrm{M}$ ethylenediamine tetra-acetic acid (EDTA) and mixed with 6\% dextran in saline solution (Solplex 70; Sifra, Verona, Italy) and $30 \mathrm{mM}$ dextrose (Sigma Chemical Co., St Louis, USA). The cells were allowed to sediment for 60-90 $\mathrm{min}$ at room temperature, according to Lichtenstein and OsLer [20]. The leucocyte-rich plasma was centrifuged at $300 \times \mathrm{g}$ for $15 \mathrm{~min}$ at $4^{\circ} \mathrm{C}$, and the cell button was washed twice in Tyrode's buffer, $\mathrm{pH}$ 7.4, containing (mM): $\mathrm{NaCl} \mathrm{140;} \mathrm{dextrose} \mathrm{5.5;}$ $\mathrm{KCl} 2.2 ; \mathrm{NaH}_{2} \mathrm{PO}_{4} 0.36 ; \mathrm{NaHCO}_{3}$ 12. The cells were then suspended in Tyrode's buffer with $1.8 \mathrm{mM} \mathrm{CaCl}_{2}$ and $0.5 \mathrm{mM} \mathrm{MgCl}_{2}$. These suspensions in Tyrode's buffer were utilized to evaluate histamine release in control conditions. To investigate the effects of $\mathrm{Na}^{+}$on histamine release, $\mathrm{NaCl}$ was replaced with the chloride salt of choline, a nonpermeating $\mathrm{Na}^{+}$analogue. When the $\mathrm{NaCl}$ concentration was reduced, the concentration of choline chloride was increased correspondingly to maintain a constant $140 \mathrm{mM}$ of the two cations together. Leucocyte suspensions were also prepared with isotonic N-methylD-glucamine (Sigma Chemical Co. Ltd) solutions. The osmolarity of the solutions employed was checked with an osmometer, and ranged 270-300 $\mathrm{mOsm} \cdot \mathrm{L}^{-1}$.

Basophil concentration in leucocyte suspensions was evaluated by alcian blue staining [21], and subsequent counting in a Fuchs-Rosenthal chamber (Walter Schrenk, Hofheim am Taunus, Germany). When cell viability was assessed by trypan blue (provided by Farmacia Ospedale Maggiore Policlinico, Milan, Italy) exclusion, all the leucocyte suspensions were more than $95 \%$ viable.

\section{Evaluation of the effect of serum on the inhibitory effect of $\mathrm{Na}^{+}$}

To investigate whether the effect of $\mathrm{Na}^{+}$on basophil histamine release is influenced by a soluble serum factor, basophils from healthy subjects were incubated with sera from allergic patients for $60 \mathrm{~min}$ at $37^{\circ} \mathrm{C}$, following the method used for passive sensitization [22]. The sera were taken from allergic patients who had already shown an impaired inhibitory effect of $\mathrm{Na}^{+}$on $\mathrm{IgE}$ mediated basophil histamine release. Control incubation with buffer was performed. After incubation, leucocyte suspensions were centrifuged at $300 \times \mathrm{g}$ for $15 \mathrm{~min}$ at $4^{\circ} \mathrm{C}$, washed in Tyrode's buffer, and resuspended in high and low $\mathrm{Na}^{+}$ solutions. Basophil stimulation with anti-IgE and IL-3 was then carried out.

\section{Histamine release from leucocyte suspensions}

Leucocyte stimulation was performed in 12 by 75 mm polyethylene tubes (LP Italiana, Milan, Italy). Briefly, $2-4 \times 10^{4}$ basophils, suspended in $0.5 \mathrm{~mL}$ Tyrode's buffer or choline chloride solution, were added to prewarmed tubes $\left(37^{\circ} \mathrm{C}\right)$ containing $0.5 \mathrm{~mL}$ of the same solution with polyclonal goat anti-human IgE, $\varepsilon$-chain specific, (Sigma Chemical Co. Ltd, final dilutions of $1 / 5 \times 10^{5}, 1 / 5 \times 10^{4}$ and $1 / 5 \times 10^{3}$, corresponding to protein concentrations of $0.1,1$ and $10 \mu \mathrm{g} \cdot \mathrm{mL}^{-1}$, respectively), $\mathrm{N}$-formyl-methionylleucyl-phenylalanine (FMLP) (Sigma Chemical Co. Ltd, concentrations ranging $10^{-8}-10^{-6} \mathrm{M}$ ) or recombinant human IL-3 (purchased from Amersham, Aylesbury, UK; concentrations ranging $\left.0.1-10 \mathrm{ng} \cdot \mathrm{mL}^{-1}\right)$. After mixing and incubating for $60 \mathrm{~min}$ at $37^{\circ} \mathrm{C}$, the reaction was stopped by cooling the tubes at $40^{\circ} \mathrm{C}$ and by centrifuging at $1,000 \times \mathrm{g}$ for $20 \mathrm{~min}$ at the same temperature. After centrifugation, the supernatants were aspirated, mixed with an equal volume of $6 \% \mathrm{HClO}_{4}$ and centrifuged at $2,000 \times \mathrm{g}$ for $15 \mathrm{~min}$ at $40^{\circ} \mathrm{C}$. Histamine concentration in the supernatants was measured using an automated fluorometric technique [23]. Spontaneous histamine release 
was evaluated by measuring histamine concentration in the supernatant of unstimulated cells; total histamine content was obtained by adding $0.5 \mathrm{~mL} 6 \% \mathrm{HClO}_{4}$ to $0.5 \mathrm{~mL}$ cell suspension. Net histamine release induced by secretagogues was calculated as percentage of total histamine content after subtraction of spontaneous release.

Every experiment was carried out in duplicate, and the average difference between replicate determinations was less than $10 \%$. None of the reagents employed in this study interfered with the fluorometric determination of histamine concentration or modified cell viability, as assessed by trypan blue exclusion.

\section{Statistical analysis}

The Instat statistical software package (Graphpad software, San Diego, CA, USA) was used for statistical analysis. The results were expressed as the mean \pm SEM. Significant differences were assessed with the two-tailed Student's t-test for paired and unpaired data. Correlation was evaluated by linear regression, calculated according to the least squares method. A p-value lower than 0.05 was considered to be significant.

\section{Results}

The mean percentage of spontaneous histamine release during a 60 min leucocyte incubation in standard Tyrode's buffer was $4.0 \pm 1.0 \%$ in allergic patients and $1.5 \pm 0.1 \%$ in control subjects, with a significant difference between the two populations $(\mathrm{p}<0.01)$. As no difference was found between rhinitics and asthmatics, the data from these two populations were pooled. $\mathrm{Na}^{+}$removal from extracellular medium caused significant increase of spontaneous histamine release in control subjects $(4.0 \pm 0.5 \% ; \mathrm{p}<0.001)$ but not in allergic patients $(5.5 \pm 0.8 \%$; NS).

Basophil stimulation with anti-IgE caused a dosedependent histamine release, the highest response occurring when anti-IgE was used at the dilution of $1 / 5 \times 10^{3}$ both in allergic patients $(36 \pm 4 \%)$ and in healthy subjects $(26 \pm 3 \%)$ (fig. 1). The results from rhinitics and
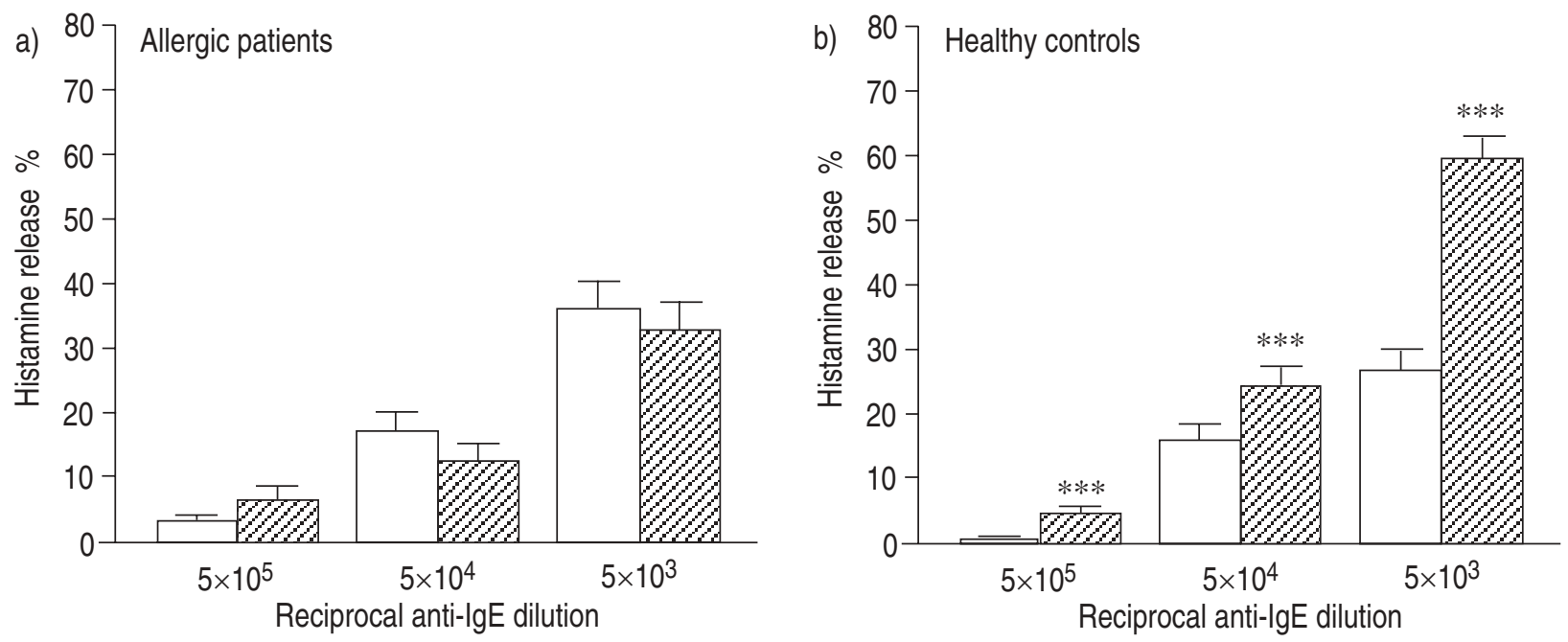

Fig. 1. - Anti-IgE-induced histamine release from basophils of: a) patients with allergic rhinitis $(\mathrm{n}=24)$ and allergic asthma ( $\mathrm{n}=10)$ and; b) healthy controls $(\mathrm{n}=41)$ suspended in high $(\square)$ and low $(\mathscr{2}) \mathrm{Na}^{+}$solutions. The results are expressed as mean \pm sem. $* * *$ : $<<0.001$ vs release obtained in high $\mathrm{Na}^{+}$. IgE: immunoglobulin E. 


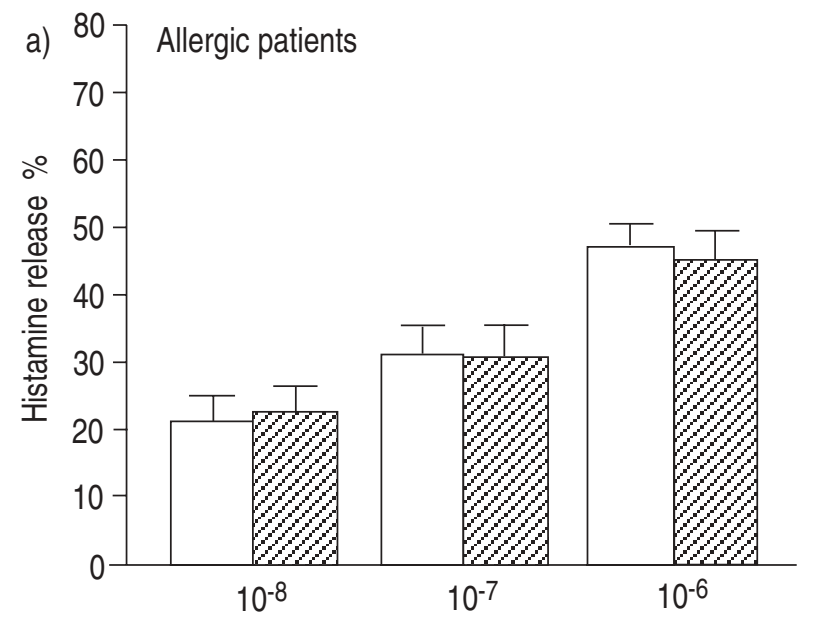

FMLP concentration M

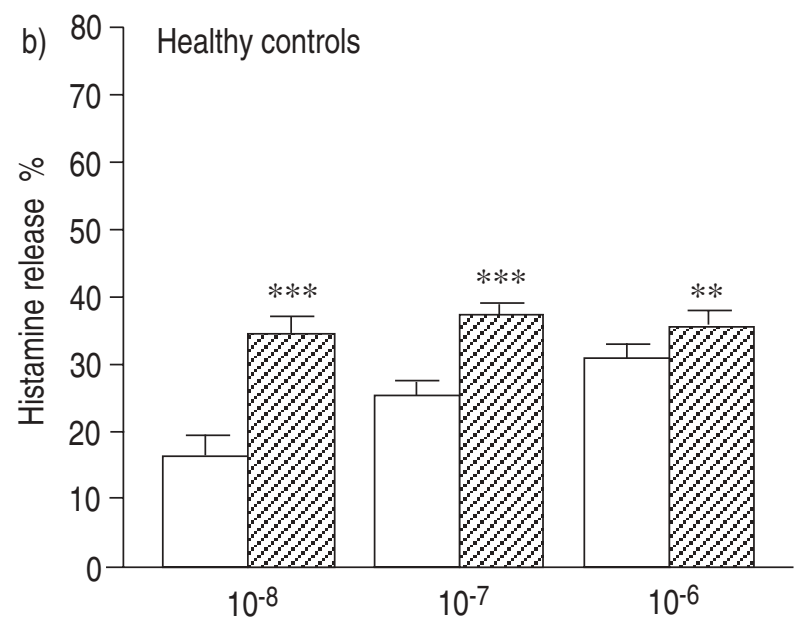

FMLP concentration M

Fig. 2. - FMLP-induced histamine release from basophils of: a) patients with allergic rhinitis ( $\mathrm{n}=24)$ and allergic asthma (n=10) and; b) healthy controls $(\mathrm{n}=41)$ suspended in high $(\square)$ and low $(\angle 2 Q) \mathrm{Na}^{+}$solutions. The results are expressed as mean \pm SEM. $* * *$ : $\mathrm{p}<0.001$ vs release obtained in high $\mathrm{Na}^{+}$; **: $\mathrm{p}<0.01$ vs release obtained in high $\mathrm{Na}^{+}$. FMLP: N-formyl-methionyl-leucyl-phenylalanine.

$10^{-6} \mathrm{M}(47 \pm 4$ vs $31 \pm 2 \%$; $\mathrm{p}<0.01)$. When leucocytes were suspended in a low $\mathrm{Na}^{+}$solution, a significant increase of FLMP-induced histamine release was observed in the controls $\left(10^{-7}\right.$ M FMLP: $25 \pm 2 \%$ in high $\mathrm{Na}^{+}$vs $36 \pm 2 \%$ in low $\left.\mathrm{Na}^{+} ; \mathrm{p}<0.001\right)$, but not in the allergic patients $\left(32 \pm 4 \%\right.$ in high $\mathrm{Na}^{+}$vs $31 \pm 5 \%$ in low $\mathrm{Na}^{+}$; NS). The effect of $\mathrm{Na}^{+}$removal in normal subjects was more marked at the lowest FMLP concentration used.

The increase in $\mathrm{Na}^{+}$concentration in the extracellular medium was accompanied by a dose-dependent inhibition of anti-IgE- and FMLP-induced histamine release in normal subjects, but not in allergic patients (fig. 3). In normal subjects, histamine release was maximal at 0 $\mathrm{mM} \mathrm{NaCl}$ and minimal at the physiological concentration of $140 \mathrm{mM} \mathrm{NaCl}$. Conversely, in allergic patients anti-IgE- and FMLP-induced histamine release at $0 \mathrm{mM}$ $\mathrm{NaCl}$ was not significantly different from the values obtained at $140 \mathrm{mM} \mathrm{NaCl}$.

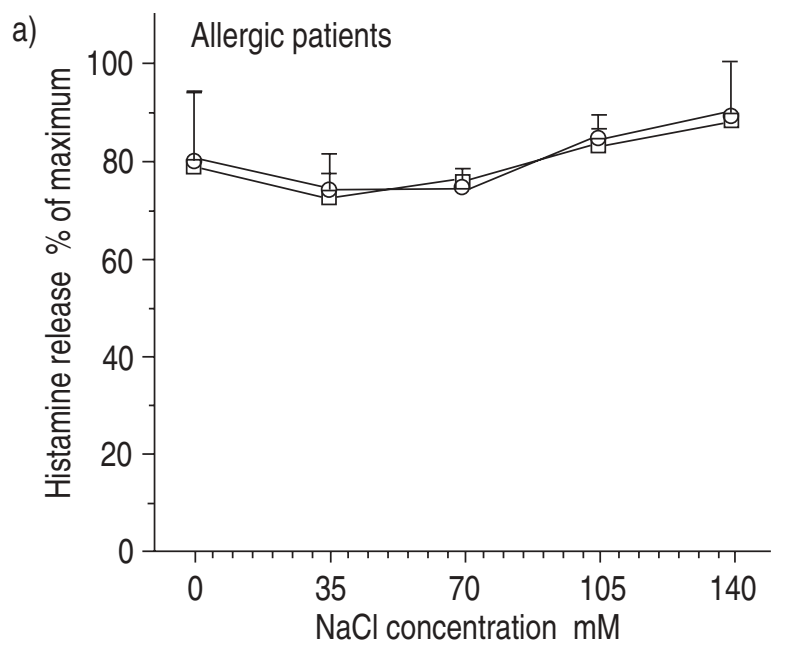

In standard Tyrode's buffer, IL-3 $\left(10 \mathrm{ng} \cdot \mathrm{mL}^{-1}\right)$ provoked a histamine release $>5 \%$ of total histamine content in 10 out of $34(29 \%)$ allergic patients and in 2 out of $16(12 \%)$ healthy subjects. Mean histamine release induced by 10 $\mathrm{ng} \cdot \mathrm{mL}^{-1} \mathrm{IL}-3$, a concentration which has been shown to be optimal for histamine release [15], was $3.2 \pm 0.8 \%$ in healthy subjects and $5.7 \pm 2.1 \%$ in allergic patients, with a trend towards a higher response in the latter population (fig. 4). Removal of extracellular $\mathrm{Na}^{+}$caused a significant increase of histamine release in normal subjects, but not in allergic patients (histamine release induced by $10 \mathrm{ng} \cdot \mathrm{mL}^{-1}$ in low $\mathrm{Na}^{+}$was $43 \pm 4 \%$; $<<0.001$ in healthy subjects and $12 \pm 2 \%$; NS in allergic patients).

The subjects were divided into three groups according to the intensity of basophil response. Basophils releasing $0-20 \%$ of total histamine content were considered low releasers; an intermediate response ranged 20-50\%; whereas, above $50 \%$ the response was considered high.

b)

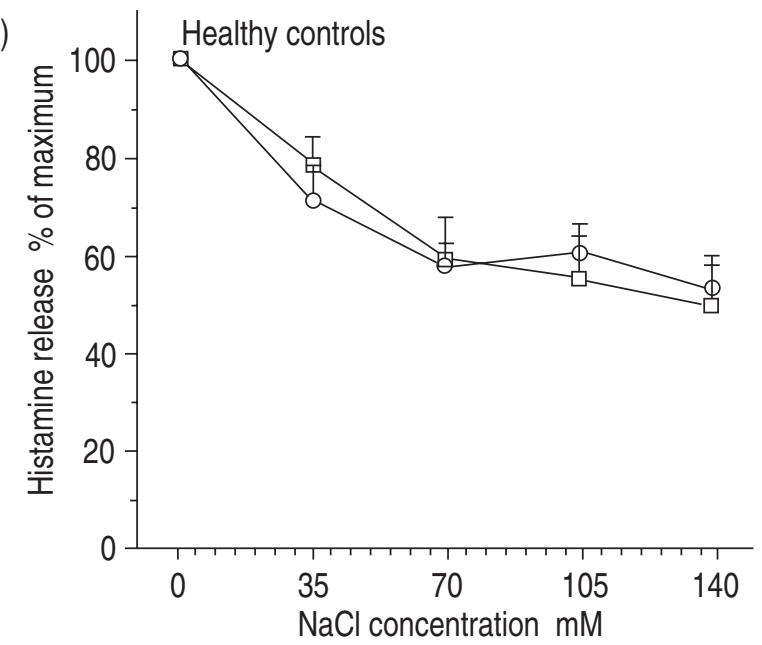

Fig. 3. - Effects of different extracellular $\mathrm{NaCl}$ concentrations on anti-IgE- $\left(1 / 5 \times 10^{3} ;-\square-\right)$ and FMLP- $\left(10^{-6} \mathrm{M}\right.$; $\left.-0-\mathrm{O}_{-}\right)$induced histamine release in: a) allergic patients $(\mathrm{n}=3)$ and; b) healthy controls $(\mathrm{n}=8)$. In low $\mathrm{Na}^{+}$solutions, $\mathrm{NaCl}$ was isosmotically replaced with choline chloride. The results are expressed as mean percentage of maximum release. For the controls, histamine release was significantly $(\mathrm{p}<0.05)$ lower at all $\mathrm{NaCl}$ concentrations than in the presence of $140 \mathrm{nM}$ choline chloride $(0 \mathrm{mM} \mathrm{NaCl})$. In contrast, in allergic patients histamine release in low Na+ was not significantly different from histamine release in the presence of $\mathrm{NaCl}$ at any concentration. IgE: immunoglobulin E; FMLP: N-formylmethionyl-leucyl-phenylalanine. 

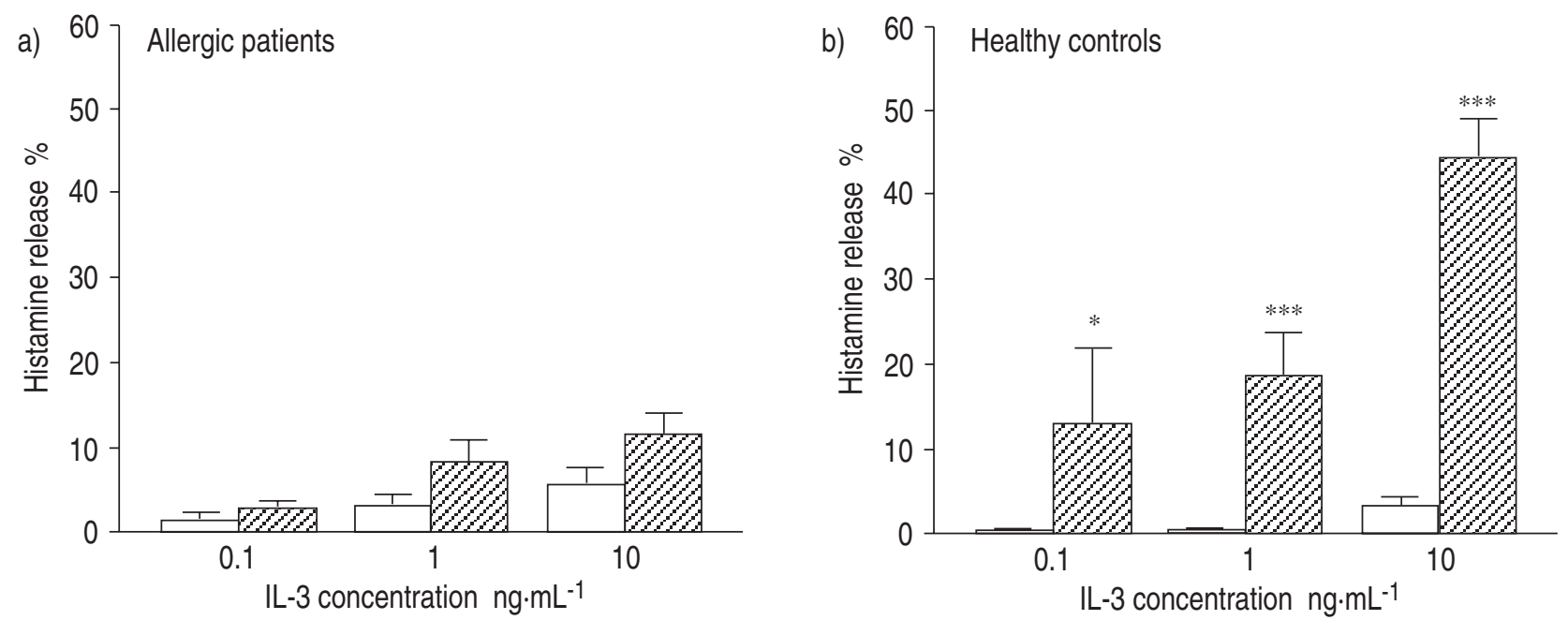

Fig. 4. - IL-3-induced histamine release from basophils of: a) patients with allergic rhinitis ( $\mathrm{n}=24)$ and allergic asthma ( $\mathrm{n}=10)$ and; $\mathrm{b}$ ) healthy controls $(\mathrm{n}=16)$ suspended in high $(\square)$ and low $(Q 22) \mathrm{Na}^{+}$solutions. The results are expressed as mean \pm SEM. $* * *: \mathrm{p}<0.001$ vs release obtained in high $\mathrm{Na}^{+}$; *: $\mathrm{p}<0.05$ vs release obtained in high $\mathrm{Na}^{+}$. IL-3: interleukin-3.

A higher percentage of high releasers was found among the allergics than among the controls ( 29 and $12 \%$, respectively). $\mathrm{Na}^{+}$removal did not cause an increase in histamine release in allergic patients independently of the basophil responsiveness. Conversely, in control subjects $\mathrm{Na}^{+}$removal caused a significant increase of histamine release induced by anti-IgE $\left(1 / 5 \times 10^{3}\right)$, which was unrelated to the basophil responsiveness (fig. 5). Similar findings were obtained with FMLP.

Basophils from control subjects were incubated with sera from allergic patients, washed and resuspended in high and low $\mathrm{Na}^{+}$solutions. This procedure failed to influence basophil behaviour significantly (table 2). $\mathrm{Na}^{+}$ substitution with N-methyl-D-glucamine led to a significant increase of histamine release regardless of previous basophil incubation with buffer or allergic sera.



Fig. 5. - Effect of extracellular $\mathrm{Na}^{+}$on basophil histamine release induced by an optimal dose of anti-IgE (dilution $1 / 5 \times 10^{3}$, protein content $\left.10 \mu \mathrm{g} \cdot \mathrm{mL}^{-1}\right)$ in: a) allergic patients $(\mathrm{n}=34)$ and; b) healthy subjects $(n=41)$. The subjects were divided into three groups (low, intermediate and high releasers) according to the basophil responsiveness (see table 2). For each group, histamine release in high $\mathrm{Na}^{+}$ was compared to histamine release in low $\mathrm{Na}^{+}$. The results are expressed as mean \pm SEM. $\$$ : $\mathrm{p}<0.0001$ vs release obtained in high $\mathrm{Na}^{+}$.

\section{Discussion}

It has been demonstrated that $\mathrm{Na}^{+}$downregulates $\mathrm{IgE}$ mediated histamine release from basophils of healthy subjects $[12,13]$ and that the inhibitory effect of $\mathrm{Na}^{+}$ is impaired in patients with allergic rhinitis [16]. The present results indicate that the defective inhibition of $\mathrm{Na}^{+}$is present in allergics (both patients with allergic rhinitis and asthmatics), and that it concerns basophil histamine release induced by $\operatorname{IgE}$-dependent (anti-IgE) and IgE-independent (FMLP, IL-3) stimuli. These data also show that basophils from patients with respiratory allergy are more prone to release histamine spontaneously or in response to anti-IgE, FMLP and IL-3 than basophils from healthy subjects. This finding may have a clinical relevance, since it has been demonstrated that the severity of allergic symptoms is correlated with basophil sensitivity to antigen stimulation in vitro [8].

Initially, it was supposed that basophil releasability was almost exclusively linked to intrinsic factors, but evidence has been collected in recent years that extrinsic factors, such as IgE, cytokines and other soluble factors, can influence mediator release from basophils. We have found, in fact, that $\operatorname{IgE}$ may have a different sensitizing capacity [24], and this may influence the efficiency of the basophil/IgE system. This observation has been confirmed and extended by MACDONALD et al. [25], who have shown that atopic subjects have a type of $\operatorname{IgE}$ (designated $\operatorname{IgE}+$ ), which has a particular ability to activate basophils. According to these authors, the presence of $\mathrm{IgE}+$ is almost entirely restricted to atopic subjects and correlates with disease severity. IL-3, interleukin-5 (IL5) and granulocyte/macrophage colony-stimulating factor (GM-CSF) have been identified as the cytokines with the strongest activity on basophil histamine release [26-28]. Furthermore, chemokines and histamine-releasing factors secreted by mononuclear cells and other inflammatory cells can directly induce histamine release from basophils [29-32]. Indeed, the ability of basophils to release histamine may be the consequence both of intrinsic cellular properties and extrinsic factors, such as IgE, cytokines and histamine-releasing factors. The control mechanisms of basophil histamine release are 
Table 2. - Effect of the incubation with sera from allergic patients on histamine release from basophils of healthy subjects suspended in high and low $\mathrm{Na}^{+}$solutions

\begin{tabular}{|c|c|c|c|c|c|c|c|c|}
\hline & \multicolumn{4}{|c|}{ Incubation with buffer } & \multicolumn{4}{|c|}{ Incubation with allergic serum } \\
\hline & High $\mathrm{Na}^{+}$ & Low $\mathrm{Na}^{+}$ & Difference & p-value & High $\mathrm{Na}^{+}$ & Low $\mathrm{Na}^{+}$ & Difference & $\mathrm{p}$-value \\
\hline Anti-IgE & $9.8 \pm 2.5$ & $22.2 \pm 23.9$ & $12.4 \pm 1.2$ & $<0.01$ & $10.3 \pm 1.3$ & $21.2 \pm 1.2$ & $10.9 \pm 1.3$ & $<0.0001$ \\
\hline IL-3 & $1.5 \pm 0.6$ & $8.2 \pm 1.0$ & $6.7 \pm 0.8$ & $<0.01$ & $0.1 \pm 0.1$ & $3.1 \pm 0.8$ & $2.9 \pm 0.8$ & $<0.006$ \\
\hline
\end{tabular}

Leucocytes from healthy subjects $(n=4)$ were incubated for $60 \mathrm{~min}$ at $37^{\circ} \mathrm{C}$ with buffer or with sera from allergic patients $(n=4)$, washed, resuspended in high $(140 \mathrm{mM} \mathrm{NaCl})$ and low $\left(140 \mathrm{mM} \mathrm{N}\right.$-methyl-D-glucamine) $\mathrm{Na}^{+}$solutions, and stimulated with anti$\mathrm{IgE}$ and IL-3. The results are expressed as net percentage histamine release and represent the mean \pm SEM of seven experiments, since leucocytes from three normal subjects were incubated with sera of two different allergic patients. A defective inhibition by $\mathrm{Na}^{+}$on basophil histamine release had previously been found in the allergic patients selected for the experiments. The incubation with sera from allergic patients failed to significantly influence the inhibitory effect of $\mathrm{Na}^{+}$on histamine release from normal basophils. IgE: immunoglobulin-E; IL-3: interleukin-3.

numerous and complex: on the basis of present knowledge, it is difficult to ascribe the enhanced basophil releasability of patients with respiratory allergy to a single factor, either intrinsic or extrinsic.

A great variability of basophil response to activating agents was observed both in allergic patients and healthy subjects. To evaluate whether the failure to find an inhibitory effect of $\mathrm{Na}^{+}$in allergic patients was related to the higher frequency of high releasers, the patients and the control subjects were divided into three groups according to the magnitude of basophil response, and the behaviour was examined in a low $\mathrm{Na}^{+}$medium. Different responses were found in controls and allergics which were independent of the basophil histamine releasability. Therefore, the defective inhibition by $\mathrm{Na}^{+}$is typical of the allergic status and is unrelated to the intensity of basophil response. This failure in the inhibitory effect of $\mathrm{Na}^{+}$may be one of the factors responsible for the enhanced basophil releasability in allergics.

It has been demonstrated that the inhibitory effect of $\mathrm{Na}^{+}$is linked to its intracellular concentration, and the mechanism of action is probably related to the modulation of membrane potential and intracellular $\mathrm{pH}[13$, $15,33]$. The defective inhibition of $\mathrm{Na}^{+}$on basophil histamine release in allergic patients could be due to an intrinsic basophil abnormality or to the effect of an extrinsic (soluble) factor. To further investigate this point, basophils from healthy subjects were incubated with sera from atopic patients and then stimulated in high and low $\mathrm{Na}^{+}$solutions. The incubation with sera from allergic patients failed to influence the behaviour of normal basophils in a significant way. These data apparently suggest that the reduced sensitivity to the inhibitory effect of $\mathrm{Na}^{+}$in allergic patients is due to an intrinsic cellular abnormality rather than to a soluble serum factor. This finding should, however, be interpreted cautiously, since we cannot ignore the fact that serum freezing, storage and thawing may have altered the capacity to influence basophil behaviour in a low$\mathrm{Na}^{+}$medium. The reduced sensitivity to the inhibitory effect of $\mathrm{Na}^{+}$in allergics could, in fact, be the result of cellular priming, possibly due to cytokines or other soluble factors with a consequent active status of receptors. Another explanation of the defective $\mathrm{Na}^{+}$inhibition could be an alteration in the mechanisms in either of $\mathrm{Na}^{+}$loading or $\mathrm{Na}^{+}$depletion in basophils from allergic patients.

Some alterations regarding $\mathrm{Na}^{+}$transport and metabolism have been observed in allergic patients, SKONER et al. [17] have documented a reduction of $\mathrm{Na}^{+}, \mathrm{K}^{+}$ adenosine triphosphate (ATPase) enzyme activity in the platelets of allergic patients, due to a circulating inhibitor, and this in turn could influence the intracellular concentration of these monovalent cations. TRIBE et al. [18] have shown that patients with airway hyperreactivity have an increased $\mathrm{Na}^{+}$influx into peripheral blood leucocytes, stimulated by a serum-borne factor. An increased $\mathrm{Na}^{+}$influx and an inhibited $\mathrm{Na}^{+}, \mathrm{K}^{+}$ATPase could have profound effects on $\mathrm{Na}^{+}$homeostasis and, in particular, on $\mathrm{Na}^{+} / \mathrm{Ca}^{2+}$ exchanges. These alterations could influence the functional activity of several cell types, including basophils. As yet, little is known about ion pathways through the basophil membrane. Preliminary data indicate that IgE-dependent activation of human basophils leads to the opening of nonselective cation channels [34]. Furthermore, it seems that $\mathrm{Na}^{+} / \mathrm{Ca}^{2+}$ exchange is operating in human basophils, and that IL-3 exerts its enhancing effect on IgE-mediated histamine release by promoting the exchange of intracellular $\mathrm{Na}^{+}$with extracellular $\mathrm{Ca}^{2+}$ [35]. Further studies are needed in order to investigate how the nonselective cation channels and the $\mathrm{Na}^{+} / \mathrm{Ca}^{2+}$ exchanger operate in basophils from healthy subjects and atopic patients.

In conclusion, our data indicate that basophils from patients with allergic rhinitis or allergic bronchial asthma release more histamine than basophils from healthy subjects either spontaneously or on challenge with antiimmunoglobulin-E, N-formyl-methionyl-leucyl-phenylalanine and interleukin-3. Furthermore, at physiological concentrations, $\mathrm{Na}^{+}$exerts an inhibitory effect on basophil histamine release in healthy subjects. but not in atopic patients. The impairment of the inhibitory effect of $\mathrm{Na}^{+}$ may be one of the causes of the enhanced basophil histamine release in patients with respiratory allergy.

\section{References}

1. Ishizaka $\mathrm{T}$, DeBernardo $\mathrm{R}$, Tomioka $\mathrm{H}$, Lichtenstein LM, Ishizaka K. Identification of basophil granulocytes as a site of allergic histamine release. J Immunol 1972; 108: 1000-1004.

2. Conroy MC, Adkinson NF Jr, Lichtenstein LM. Measurement of IgE on human basophils: relation to serum IgE and anti-IgE-induced histamine release. J Immunol 1977; 118: 1317-1321.

3. Lichtenstein LM, MacGlashan DW Jr. The concept of basophil releasability. J Allergy Clin Immunol 1986; 77 : 291-294. 
4. Lichtenstein LM, Conroy MC. The "releasability" of mediators from human basophils and granulocytes. Proceedings of the IXth International Congress of Allergology. Amsterdam, Excerpta Medica, 1977; pp. 109-115.

5. Busse W, Swenson CA, Sharpe G, Koschat M. Enhanced basophil histamine release to concanavalin $\mathrm{A}$ in allergic rhinitis. J Allergy Clin Immunol 1986; 78: 90-97.

6. Assem ESK, Attallah NA. Increased release of histamine by anti-IgE from leucocytes of asthmatic patients and possible heterogeneity of IgE. Clin Allergy 1981; 11: 367-374.

7. Gaddy NK, Busse WW. Enhanced IgE-dependent basophil histamine release and airway reactivity in asthma. Am Rev Respir Dis 1984; 134: 969-974.

8. Lichtenstein LM, Norman PS, Winkenwerder WL. Clinical and in vitro studies on the role of immunotherapy in ragweed hay fever. Am J Med 1968; 44: 514-524.

9. Sparrow D, O'Connnor GT, Rosner B, Weiss ST. Predictors of longitudinal change in methacholine-airway responsiveness among middle-aged and older men: the normative aging study. Am J Respir Crit Care Med 1994: 149: 376-381.

10. Tedeschi A, Palella M, Arquati M, Milazzo N, Miadonna A. Ionic regulation of human basophil releasability. III. Effects of $\mathrm{Na}^{+}$and $\mathrm{Ca}^{2+}$ on histamine release induced by different stimuli. Pharmacol Res 1994: 30: 229-241.

11. MacGlashan D Jr, Botana LM. Biphasic $\mathrm{Ca}^{2+}$ responses in human basophils: evidence that the initial transient elevation associated with the mobilization of intracellular calcium is an insufficient signal for degranulation. J Immunol 1993; 150: 980-991.

12. Tedeschi A, Arquati M, Lorini M, Miadonna A. Differential effect of hypertonicity on FMLP-, anti-IgE- and $\mathrm{Ca}^{2+}$ ionophore A23187-induced histamine release from human basophil leucocytes. Int Arch Allergy Appl Immunol 1990; 93: 359-364.

13. Beauvais F, Shimahara T, Inoue I, Hieblot C, Burtin C, Benveniste J. Regulation of human basophil activation. II. Histamine release is potentiated by $\mathrm{K}^{+}$efflux and inhibited by $\mathrm{Na}^{+}$influx. J Immunol 1992; 48: 149-154.

14. Tedeschi A, Arquati M, Palella M, Milazzo N, Miadonna A. Ionic regulation of human basophil releasability. II. Nonreleasing basophils are converted into releasing basophils in a low-Na+ medium. Clin Exp Allergy 1994; 24: 66-72.

15. Tedeschi A, Palella M, Milazzo N, Lorini M, Miadonna A. IL-3-induced histamine release from human basophils: dissociation from cationic dye-binding and down-regulation by $\mathrm{Na}^{+}$and $\mathrm{K}^{+}$. J Immunol 1995; 155: 26522660.

16. Beauvais F, Hieblot C, Burtin C, Benveniste J. Regulation of human basophil activation. III. Impairment of the inhibitory effect of $\mathrm{Na}^{+}$on IgE-mediated histamine release in patients with allergic rhinitis. J Allergy Clin Immunol 1992; 90: 52-58.

17. Skoner DP, Gentile D, Evans RW. A circulating inhibitor of the platelet $\mathrm{Na}^{+}, \mathrm{K}^{+}$adenosine triphosphatase (ATPase) enzyme in allergy. J Allergy Clin Immunol 1991; 87: 476-482.

18. Tribe RM, Bouton JR, Poston L. Burney PGJ. Dietary sodium intake, airway responsiveness, and cellular sodium transport. Am J Respir Crit Care Med 1994; 149: 146-133.

19. Orlov SN, Baranova IA, Pokudin NI, Kubatiev AA, Chuchalin AG. Red blood cell transport of monovalent ions and calcium in patients with bronchial asthma.
Vestnik Akademia Meditsinskikh Nauk 1991; 3: 4349.

20. Lichtenstein LM, Osler AG. Studies on the mechanisms of hypersensitivity phenomena. IX. Histamine release from human leucocytes by ragweed pollen antigen. $J$ Exp Med 1964; 120: 507-530.

21. Gilbert HS, Ornstein L. Basophil counting with a new staining method using alcian blue. Blood 1975; 46: 279-286.

22. Levy DA, Osler A. Studies on the mechanisms of the hypersensitivity phenomena. XIV. Passive sensitization in vitro of human leucocytes to ragweed pollen antigen. J Immunol 1966; 97: 203-209.

23. Ruff F, Saindelle A, Dutripon E, Parrot JL. Continuous automatic fluorometric evaluation of total blood histamine. Nature 1967; 214: 279-281.

24. Miadonna A, Tedeschi A, Leggieri E, Froldi M, Zanussi C. Functional characterization of specific IgE antibodies for tetanus toxoid. Ricerca Clin Lab 1983; 13: 235245.

25. MacDonald SM, Lichtenstein LM, Proud D, et al. Studies of IgE-dependent histamine-releasing factors: heterogeneity of IgE. J Immunol 1987; 139: 506-512.

26. Hirai K. Morita Y, Misaki Y, et al. Modulation of human basophil histamine release by hemopoietic growth factors. J Immunol 1988; 141: 3958-3964.

27. Alam R. Welter JB, Forsythe PA, Lett-Brown MA, Grant JA. Comparative effect of recombinant IL-1, -2, -3, -4, and -6 , IFN- $\gamma$, granulocyte-macrophage colony-stimulating factor, tumor necrosis factor- $\alpha$, and histaminereleasing factors on the secretion of histamine from basophils. J Immunol 1989; 142: 3431-3435.

28. Miadonna A, Roncarolo MG, Lorini M, Tedeschi A. Inducing and enhancing effects of IL-3, -5 , and -6 and GM-CSF on histamine release from human basophils. Clin Immunol Immunopathol 1993; 210-215.

29. Kuna P, Reddigari S, Schall TJ, Rucinski D, Sadick M, Kaplan AP. Characterization of the human basophil response to cytokines, growth factors, and histamine releasing factors of the intercrine/chemokine family. $J$ Immunol 1993; 150: 1932-1943.

30. Thueson DO, Speck LS, Lett-Brown MA, Grant JA. Histamine releasing activity (HRA). I. Production by mitogen- or antigen-stimulated human mononuclear cells. J Immunol 1979; 123: 626-632.

31. Thueson DO, Speck LS, Lett-Brown MA, Grant JA. Histamine releasing activity (HRA). II. Interaction with basophils and physicochemical characterization. J Immunol 1979; 123: 633-639.

32. Alam R, Forsythe PA, Rankin JA, Boyars MC, LettBrown MA, Grant JA. Sensitivity of basophils to histamine-releasing factor(s) of various origin: dependency on allergic phenotype of the donor and surface-bound IgE. J Allergy Clin Immunol 1990; 86: 73-81.

33. Smith TF, Sanchez-Legrand F, McKean LP, Kutner MH, Cragoe RJ, Eaton DC. Role of sodium in mediator release from human basophils. J Allergy Clin Immunol 1992; 89: 978-986.

34. Beauvais F, Shimahara T, Inoue I, Benveniste J. Anti$\mathrm{IgE}$ induces the opening of nonselective cation channels on human basophils. Fund Clin Pharmacol 1994; 8: 246-250.

35. Beauvais F, Echasserieau K, Burtin C, Benveniste J. Regulation of human basophil activation: the role of $\mathrm{Na}^{+}$ and $\mathrm{Ca}^{2+}$ in IL-3-induced potentiation of IgE-mediated histamine release from human basophils. Clin Exp Immunol 1994; 95: 191-194. 